\title{
El «salvaje desenfrenado» y el «buen salvaje»: las representaciones polarizadas acerca del indígena en la prensa escrita de Perú ${ }^{1}$
}

\author{
Claudia Almeida Goshi \\ Universidad Nacional Mayor de San Marcos \\ claudia_chinita05@hotmail.com

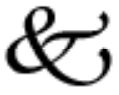

\begin{abstract}
Resumen
En el presente trabajo se emplea el marco teórico-analítico denominado Análisis Crítico del Discurso (ACD) para hallar, describir y explicar los usos de transitividad, por parte de la prensa escrita de Perú, que representen e identifiquen al indígena como el "salvaje desenfrenado» y el «buen salvaje» respecto de los discursos sobre la tragedia de Uchuraccay. En ese sentido, nuestra aproximación busca dar cuenta de modo crítico maneras de representación que la sociedad peruana hizo sobre ese luctuoso suceso. El ACD es un nuevo marco que puede desvelar las relaciones de subordinación enmascaradas por el lenguaje, de modo que se convierte en una herramienta potente de una linguística crítica y científica. Nuestra hipótesis sostiene que ambas representaciones se subtienden a partir de la misma ideología subyacente: el indígena no es ciudadano.

Palabras claves: Análisis Crítico del Discurso, transitividad, ideología, discurso y racismo.
\end{abstract}

\begin{abstract}
This paper uses an analytical and methodological approach, that is known as Critical Discourse Analysis (CDA), in order to find, describe and explain the uses of the transitivity related to murdering in Uchu-
\end{abstract}

1 Este estudio es una versión sucinta de la investigación titulada "Análisis crítico de los discursos sobre las tragedias de Uchuraccay, Lucanamarca y Putis en la prensa escrita de Perú", la cual fue sustentada el 14 de junio del 2011 en el Salón de Grados de la Facultad de Letras y CC. HH. de la UNMSM para obtener el título profesional en Linguística. 
raccay made by the Peruvian press to represent and identify indigenous people as 'a savage out of control' and 'a docile savage'. In that sense, this research tries to find ways of representation that the Peruvian society made about that lugubrious event. The CDA is a new approach that can show the power relations which are hidden by uses of language. Therefore, it is an powerful tool for a critic and scientific linguistics. Our hypothesis affirms that both representations are hold by the same hidden ideology: The indigenous person is not a citizen.

Key words: Critical Discourse Analysis, transitivity, ideology, discourse and racism.

\section{Introducción}

El conflicto armado interno (1980-2000) ha sido el episodio de violencia de mayor duración e impacto a nivel nacional debido al número de víctimas del accionar indiscriminado ejercido por las fuerzas insurgentes (sl) y contrainsurgentes (FF. AA. y Policía Nacional); así como por las pérdidas materiales ocasionadas. Los afectados, en su mayoría, fueron indígenas quechuahablantes de las zonas más excluidas y empobrecidas del país (cvr, 2004), «cuyo nombre nadie conoce ni podría recordar y cuya suerte nunca será noticia» (Manrique, 2002: 43). Estos lamentables índices de violencia sólo fueron posibles e invisibles en un país donde aún perviven los vestigios de un orden colonial excluyente a pesar de haber sido comandado por gobiernos elegidos democráticamente.

Si bien durante 1983 y 1984 se produjo el mayor número de muertes en el conflicto armado interno (Manrique, 2002 y CVR, 2004), la tragedia de Uchuraccay (26 de enero de 1983), donde ocho periodistas, su guía y un habitante de esa zona andina fueron asesinados por los residentes de esa comunidad, se convirtió en un lamentable suceso mediático que conmovió a la mayoría de la población; puesto que los hombres de prensa eran parte del nosotros, ciudadanos con deberes y derechos «legítimos». En cambio, sus asesinos eran el otro, «ignorante» $\mathrm{y}$ "salvaje» respecto al nosotros (miembros del Gobierno, las FF. AA. y la ciudadanía, que ostenta derechos y deberes «legítimos»); en otras palabras, el indígena es no-ciudadano: sujeto sin voz, sin rostro y cuya humanidad es cuestionada. De este modo, la prensa escrita peruana (El Comercio, La Prensa, Expreso y El Diario Marka) no fue «neutral» ni «objetiva», sino representó y construyó la identidad del indígena a través de usos del lenguaje (discursos) como un ente diferente que ataca instintivamente por ser «ignorante» $\mathrm{y}$ «salvaje».

La presente investigación está constituida por cuatro partes: en primer lugar, se desarrollarán, de manera sucinta, algunos pilares teóricos del Análisis Crítico del Discurso (ACD), marco empleado en nuestro estudio; en segundo lugar, se presentará el análisis de los datos, conformado por la metodología 
del trabajo y la ejemplificación y la explicación del empleo de la transitividad por parte de la prensa escrita de Perú acerca de la tragedia de Uchuraccay; en tercer lugar, se expondrán las conclusiones de la investigación y, por último, las referencias bibliográficas utilizadas.

La noción constructivista del discurso es una de las piezas angulares del marco teórico-analítico denominado $\mathrm{ACD}$, enfoque sociolinguiístico que desentraña la naturaleza social del lenguaje, ya que todo fenómeno linguiístico es compartido y constituye la «realidad» (Fairclough, 2008). Por otro lado, el objetivo principal de esta disciplina es explicitar aquellos usos del lenguaje que naturalicen formas de inequidad social para contribuir al cambio que garantice la manumisión de los grupos oprimidos; por ello, los linguiistas críticos son aquellos que analizan los discursos por motivos políticos (Mills, 1997). El cambio y la resistencia son enarbolados por el acd a pesar de que posean cierta pátina utópica: sí son posibles si es que los individuos desarrollan una conciencia crítica respecto a las ideologías naturalizadas, es decir, aquellas representaciones de la «realidad» que sustentan formas de dominación social y que se asumen como «inevitables» e «inmodificables» (Cameron, 2001). De acuerdo con Fairclough (1992), el término discurso ha sido utilizado en Linguiística ${ }^{2}$ para referirse tanto al lenguaje hablado como escrito; sin embargo, el discurso es interpretado por el linguiista inglés como lenguaje en uso (escrito u oral), como una forma de práctica social. Esto implica, en primer lugar, que el discurso es un modo de acción, una manera de hacer las cosas, caminos para representar y constituir la «realidad»; en segundo lugar, el discurso entraña una relación dialéctica entre éste y la estructura social, puesto que aquél no sólo la construye sino también está constituido por ésta.

El discurso puede construir y constituir ideologías, esto es, representaciones de la «realidad» que contribuyen a la (re)producción de inequidades sociales y relaciones de poder (Fairclough, 1992). Además, es multifuncional (Fairclough, 1992 y 2008), ya que los individuos por medio de usos del lenguaje construyen y proyectan identidades (identity function), establecen y negocian relaciones sociales (relational function) y constituyen sistemas de conocimiento y de creencias (ideational function).

En el presente estudio se explora, especialmente, la función identitaria del discurso, pues la prensa escrita de Perú representa y construye polarizadamente al indígena como el «salvaje desenfrenado» y el «buen salvaje» por medio del

2 Para el paradigma formal, el discurso es un concepto referido al lenguaje más allá de la oración; en consecuencia, no puede estar conformado por sólo una oración. Asimismo, el objetivo del análisis estructural es hallar patrones (conectores, pronombres y otros mecanismos cohesivos) que provean sentido al texto como una totalidad. Este es analizado sólo por medio de las partes que lo conforman (Cameron, 2001). 
empleo de elementos del sistema de transitividad. Así, se puede manifestar que, a través de estrategias discursivas específicas que sirvieron para constituir al otro, el indígena, como "salvaje desenfrenado» y «buen salvaje», la prensa escrita naturalizó la ideología racista el indígena no es ciudadano, donde el nosotros establece relaciones de poder con el otro por medio de prácticas sociales que restringen su acceso a los bienes materiales y simbólicos (educación, medios de comunicación, entre otros). El racismo (re)producido discursivamente se convierte en cotidiano y «natural»; incluso, los discursos que representan ideologías racistas generan inequidad social, exclusión y marginación contra los grupos discriminados: «en el lenguaje se reproduce (o se refleja) una ideología dominante que sitúa al Otro como inferior» (Zavala y Zariquiey, 2007: 336). Por otro lado, el racismo no sólo se legitima o reduce en diferencias circunscritas al color de la piel (Zavala y Córdova, 2010). En Perú, país donde aún pervive un orden social excluyente, el fenotipo no determina las desigualdades étnicas; pues aquél se reconfigura o se subordina a otros factores (geográficos, educativos, etc.). Aunque el Estado haya reconocido la ciudadanía de los indígenas en 1979, en Perú se establecen brechas ciudadanas; pues no todos gozan de los mismos derechos por igual ${ }^{3}$. Los indígenas, quienes fueran las víctimas mayoritarias durante las dos décadas de la lucha armada, no son ciudadanos ${ }^{4}$ : no poseen deberes ni derechos aceptados ni reconocidos por los miembros del Gobierno, las FF. AA. ni por la ciudadanía (que sí ostenta deberes y derechos legítimos). "Los pueblos indígenas no han gozado de iguales oportunidades para ejercer sus derechos ciudadanos. Aunque se los declare iguales en derechos, en realidad no lo son. Carecen de las mismas oportunidades de vida, personales y sociales, y de ejercerlas siguiendo su propia cultura, sin interferencias ajenas» (Villoro, 1998: 102). Sin embargo, se espera demostrar en el presente trabajo que, a través de una mirada crítica desde la Linguística, se pueden encarar para poder continuar con el proceso de reconciliación nacional; ya que dicha disciplina «es una cuestión moral y puede cambiar el mundo» (Gee 2005: 203).

\section{Análisis de los datos}

A continuación, se presentan la metodología y los materiales utilizados en la presente investigación; así como el concepto de transitividad y su empleo por parte de la prensa escrita de Perú acerca de la tragedia de Uchuraccay con

3 Para López (1997), unos peruanos son más ciudadanos que otros; ya que existen ciudadanos de primera y segunda clase. Los de primera clase gozan de derechos civiles, políticos y sociales por igual; sin embargo, los de segunda clase tienen una participación exigua de tales derechos.

4 Según Villoro (1998), el derecho a la vida, a la seguridad, a la libertad y a la igualdad de trato son derechos comunes con los que todo ciudadano debe contar en un Estado multicultural, donde el reconocimiento de aquellos sea enarbolado por los diferentes pueblos. 
los que se identifica polarizadamente al otro como "salvaje desenfrenado» y «buen salvaje».

\subsection{Metodología y materiales}

El corpus del presente estudio está constituido por discursos (artículos informativos, editoriales y artículos de opinión) publicados en los diarios peruanos El Comercio, Expreso, La Prensa y El Diario Marka, hasta un mes después de acontecida la tragedia de Uchuraccay (26 de enero de 1983); es decir, se analizaron los discursos publicados desde el 27 de enero hasta el 26 de febrero de 1983. Los discursos seleccionados sobre la tragedia fueron cuatrocientos sesenta y uno: sesenta y ocho son de El Comercio; ochenta y nueve, de Expreso; noventa y nueve, de La Prensa, y doscientos cinco, de El Diario Marka. El corpus fue hallado y recolectado en la Biblioteca Central de la UNMSM por medio de fotografías digitales. Las imágenes digitales fueron procesadas y editadas con el programa Corel Draw y finalmente impresas en hojas bond A4 para facilitar la lectura y análisis de los discursos. La metodología de esta investigación se caracteriza por emplear un análisis reflexivo y sofisticado; además, se demuestra que el acd es un marco interdisciplinario, pues no sólo se utilizan herramientas linguiísticas sino también estudios surgidos en otros campos para poder explicar usos del lenguaje (discursos) como prácticas sociales.

\subsection{La transitividad}

Para Halliday (1994), la transitividad es un sistema gramatical por medio del cual se representan procesos (acción, mental, relacional) y sus participantes (agente, paciente, instrumento, entre otros); en consecuencia, este mecanismo discursivo permite la realización de la función ideacional (ideational function) del discurso, pues las experiencias de los individuos en el mundo son construidas por medio del uso de elementos del sistema de transitividad. El proceso material o de acción requiere como participantes necesariamente un agente, que hace o realiza algo, y opcionalmente un paciente, quien «sufre» la acción. Además, el proceso mental es aquel que siempre presenta un participante humano, como experimentador, que siente, piensa o percibe algo. Por otro lado, los procesos relacionales son aquellos que establecen un engarce entre dos entidades.

Factores ideológicos pueden ser relevantes respecto a las diferentes maneras de representar los procesos (Fairclough, 1992).

La transitividad es empleada para ponderar las accionas negativas del otro, explicitando la participación de los indígenas en la tragedia y las herramientas empleadas. Véase los ejemplos: 
Los comuneros de Uchuraccay les lanzaron piedras con hondas hasta dejarlos inconscientes. Posteriormente los acuchillaron, apalearon y liquidaron a machetazos. (El Dominical, suplemento semanal de El Comercio, 6-02-83, pp. 3-4.)

Al producirse el avance del grupo hacia Uchuracay, los campesinos salieron en avalancha y destrozaron a machetazos a los periodistas. ( $E x-$ preso, 31-01-83, p. 4.)

En contados minutos los ocho periodistas fueron asesinados por una población enardecida. El instinto de salvarse, los llevó a correr por varias direcciones, sin embargo, fueron cercados y uno a uno masacrados y finalmente destrozados por feroces golpes de lampa. (La Prensa, 31$01-83$, p. 4.)

Armados de piedras, palos, hondas, machetes y demás instrumentos de labranza, los campesinos rodearon a los indefensos periodistas. Ellos intentaron huir, a toda carrera. Varios llegaron a los cerros y uno a uno fueron ultimados inexorablemente por la turba. (El Diario Marka, 3101-83, p. 12.)

El indígena es agente explícito de procesos de acciones negativas en cláusulas con voz activa: ellos «lanzaron piedras», «destrozaron a machetazos». Este mismo proceso se reproduce en estructuras pasivas que también explicitan el agente a través de la introducción de la preposición por: «los ocho periodistas fueron asesinados por una población enardecida». El indígena es agente en cláusulas con voz activa o pasiva de acciones negativas que evidencian, también, la herramienta "primitiva ${ }^{5}$ empleada: piedras, machetes, cuchillos, diferentes a las que utilizaría alguien «civilizado». De esta manera, se construye al otro como un «salvaje desenfrenado» (Callirgos, 1993: 169) que mata en colectividad ( (los campesinos salieron en avalancha») con herramientas "primitivas». El indígena es agente sólo en procesos de acciones negativas y con la herramienta ("primitiva») explícita. En ninguno de los discursos analizados, el indígena es agente de otros procesos de acción: sólo cuando el otro atenta contra la humanidad del nosotros, la prensa escrita selecciona esa estructura para explicitar la participación del indígena en la tragedia. Así, el «salvajismo» del otro es (re) producido para enfatizar su diferencia y transgresión.

Los indígenas también pueden ser pacientes en otro tipo de estructuras según los siguientes ejemplos:

5 Las herramientas utilizadas por los asesinos fueron calificadas como «primitivas» en el siguiente discurso, donde se compara la tragedia de Lucanamarca con la de Uchuraccay por las armas utilizadas: «esta acción [Lucanamarca] terrorista sólo puede ser comparada con la masacre a los periodistas en Uchuraccay, por la forma en que se ha perpetrado el genocidio, utilizando armas primitivas como hachas, piedras y palos» (La Prensa, 09-04-83, p. 1.). 
[Sandro Mariátegui, presidente del senado] Comentó que los periodistas que decidieron hacer esa aventura en busca de la noticia, debieron haber solicitado la protección policial o debió haberse avisado, por algún medio, a los campesinos de la zona donde fueron muertos para evitar ese hecho lamentable. / Esto, comentó, porque los campesinos de la zona están desconfiados de la gente extraña porque ya se han cansado de ser "chantajeados" por los terroristas que han causado muchas víctimas en el departamento ayacuchano. (La Prensa, 31-01-83, p. 2.)

Por su parte, el senador de Izquierda Unida (IU), Jorge del Prado, dijo que los campesinos que asesinaron a los ocho periodistas en la localidad ayacuchana de Uchuraccay, actuaron chantajeados por los efectivos policiales y militares. (El Diario Marka, 2-2-83, p. 9)

Los indígenas son «chantajeados» por "terroristas» o "efectivos policiales» porque son incapaces de actuar individualmente. En estos discursos (publicados en el diario conservador La Prensa y el matutino contestatario El Diario Marka) donde se utilizan sólo cláusulas con voz pasiva, el indígena es paciente de las acciones de los demás (terroristas, policías o militares). No se le atribuye responsabilidad directa de los hechos. En contraposición con la representación del indígena como «salvaje desenfrenado», ahora el indígena es constituido discursivamente como «el buen salvaje»: aquel que tiene que ser guiado pasivamente por los demás y obedecerlos (Callirgos, 1993); en otros términos, puede ser fácilmente manipulable y tutelado por su falta de autonomía (Nugent, 2001 y 2010). Por otro lado, la transitividad es utilizada en discursos producidos originalmente por individuos relacionados al Gobierno (senadores), quienes ostentan las voces «autorizadas». La (re)producción de estos discursos está configurada dentro de ejercicios tutelares que implican la diferencia jerárquica entre el "tutor», el nosotros, y el "tutelado", el otro.

Véase la siguiente cita directa ${ }^{6}$ donde los indígenas son pacientes de acciones ajenas, pero en cláusulas con voz activa:

[Luis Morales Ortega, corresponsal de El Diario de Marka] "Los elementos represivos con los que el gobierno dice controlar la insurgencia de Sendero Luminoso, han bestializado a esta gente [individuos de Uchuraccay], han aprovechado sus condiciones de ignorancia, les han dado alcohol y los han empujado al asesinato. [...]. Luego les han metido en la cabeza la idea de que hay gente que se llama terrorista o guerrilleros y que son en realidad perros ladrones y asesinos, que roban y matan sin piedad; les han advertido que para defenderse de ellos tenían que hacer una sola cosa: todo aquel que llegue, todo grupo que llegue caminando a la comunidad, tenían que matarlos, extraerles los ojos, cortarles la len-

6 La cita directa reproduce fidedignamente los discursos originales a través del empleo de comillas (De Fontcuberta, 1981 y 1993). 
gua y colgarlos de las rocas para que una muerte así sirva como escarmiento para que estos perros traidores llamados terroristas no vuelvan a pasar por sus dominios". (El Diario Marka, 02-02-83, p. 5.)

Nuevamente, en este discurso producido originalmente por un periodista (de El Diario Marka, que era considerado como parte de la prensa de izquierda) se representa al indígena como un ser «manipulable» e «ignorante» que puede ser «bestializado». "Los elementos represivos» son agente explícito de procesos de acción que subordinan al paciente, «esta gente». Así, se deshumaniza al indígena y se ejerce tutela sobre él: se apela a su «ignorancia» y falta de autonomía. En consecuencia, el ejercicio tutelar no sólo es construido a través de la intertextualidad ${ }^{7}$, también es reproducido discursivamente a través del uso de cláusulas con voz pasiva o activa que presenten al indígena como paciente de las acciones ajenas.

Las estructuras ejemplificadas expresan la función ideacional (ideational function) e identitaria (identity function) del discurso porque se representa qué es lo que ocurrió, quiénes fueron los involucrados, dónde aconteció el luctuoso evento y el porqué; pero también se construyen y proyectan las identidades de los participantes. Esta convergencia se sustenta en la multifuncionalidad del discurso.

Las representaciones ${ }^{8}$ («salvaje desenfrenado» $y$ «el buen salvaje») discursivas del otro, atingentes a la identity function del discurso, construyen una visión de paralaje, esto es, las dos caras opuestas, estrechamente vinculadas, de un mismo fenómeno (Žižek, 2006). Ambas enfatizan lo negativo del otro, pero de manera diferente: el «salvaje desenfrenado» es agente de acciones negativas

7 La intertextualidad se refiere a las relaciones entre los discursos a través, generalmente, del empleo de las citas: algunas voces son recopiladas (por la prensa escrita) por ser autorizadas, mientras otras son silenciadas (Fairclough, 1995). En la versión extensa del presente estudio (ver nota $\mathrm{N} .^{\circ} 1$ ) se determinó que la prensa escrita de Perú recopila de manera directa e indirecta la voz del NOSOTROS para que ofrezca su versión de los hechos y demande el accionar del Estado para que investigue los asesinatos ocurridos en Uchuraccay a través del empleo de la intertextualidad: la voz del OTRO fue silenciada; mientras que la del NOSOTROS, escuchada. Por ello, esa manera de utilizar el mecanismo intertextual se complementa con el uso de la transitividad desarrollado en el presente trabajo; puesto que en ambas estrategias, el indígena es constituido como NO CIUDADANO.

8 Según Arrunátegui (2010), la prensa escrita peruana también produce representaciones ambivalentes acerca del indígena amazónico; pues es constituido como el nativo «odiado», «revoltoso» e «intransigente», (donde es el agente de acciones negativas), y el nativo «amado», «manipulable» $\mathrm{y}$ «desinformado», (donde el indígena amazónico es el paciente que «sufre» las acciones de otros, como las organizaciones de izquierda; así, es despojado de cualquier responsabilidad respecto a sus acciones). Ambas representaciones -de acuerdo con la autora- configuran un racismo "solapado», ya que se silencia el fenotipo del otro (el indígena amazónico) y se emplean otros criterios como la «educación» y la «inteligencia» como nuevos criterios discriminatorios. 
que utiliza herramientas "primitivas» para asesinar; mientras que «el buen salvaje» es paciente de las acciones ajenas. Esta polarización respecto a la representación del otro está enmarcada dentro de la misma ideología: el indígena no es ciudadano, dado que se cuestiona la humanidad y la autosuficiencia del otro; asimismo, se controla su representación. El nosotros construye y regula la identidad del otro. De esta manera, la «información aparentemente objetiva puede darse a conocer de modos diferentes y de esa forma parecerá creíble y será difundida» (Van Dijk, 2000: 45). El indígena no se representa a sí mismo como el nosotros porque no ejerce una ciudadanía reconocida por los demás; por eso, no es un individuo autónomo con derechos y deberes aceptados.

\section{Conclusiones}

Los discursos de la prensa escrita de Perú, acerca de la tragedia de Uchuraccay, construyeron, naturalizaron, legitimaron y racionalizaron la ideología racista el indígena no es ciudadano a través del empleo de elementos del sistema de transitividad. Así, constituyeron al otro, el indígena, como un ente deshumanizado porque no ostenta una ciudadanía reconocida por el nosotros. En otros términos, a través del empleo de la estrategia de transitividad, el otro es identificado y constituido como "el buen salvaje» o el "salvaje desenfrenado». De esta manera, la diferencia y la transgresión del otro fueron enfatizadas, y así el control que el nosotros ejerce sobre el otro se presenta como más «natural» y legítimo.

\section{Referencias bibliográficas}

ARRUNÁTEGUI, Carolina (2010). El racismo en la prensa escrita peruana / Un estudio de la representación del otro amazónico desde el Análisis crítico del discurso. Tesis de maestría en Linguística. Pontificia Universidad Católica del Perú.

CAMERON, Deborah (2001). Working with Spoken Discourse. Londres: Sage.

COMISIÓN de la Verdad y Reconciliación (2004). Hatun Willakuy. Lima: Comisión de Entrega de la CVR.

CALLIRGOS, Juan Carlos (1993). El racismo / La cuestión del otro (y de uno). Lima: Centro de Estudios y Promoción del Desarrollo, Desco.

DE FONTCUBERTA, Mar (1981). Estructura de la noticia periodística. Barcelona: A. T. E., 2. ${ }^{\text {a }}$ ed. DE FONTCUBERTA, Mar (1993). La noticia / Pistas para percibir el mundo. Barcelona: Ediciones Paidós.

FAIRCLOUGH, Norman (1992). Discourse and Social Change. Cambridge: Polity Press.

FAIRCLOUGH, Norman (1995). Media discourse. Londres: Edward Arnold.

FAIRCLOUGH, Norman (2008). «El análisis crítico del discurso y la mercantilización del discurso público: las universidades». Discurso y sociedad, vol. 2, N. ${ }^{\circ} 1$, pp. 170-185. Accesible en internet: http://www.dissoc.org/ediciones/v02n01/ DS2\%281\%29Fairclough.pdf. 
GEE, James Paul (2005). La ideología en los discursos / Lingüística social y alfabetizaciones. Madrid: Ediciones Morata S. L.

HALLIDAY, M. A. K. (1994). An Introduction to Functional Grammar. Londres: Edward Arnold.

LÓPEZ, Sinesio (1997). Ciudadanos reales e imaginarios / Concepciones, desarrollo y mapas de la ciudadanía en el Perú. Lima: Instituto de Diálogo y Propuestas.

MANRIQUE, Nelson (2002). El tiempo del miedo / La violencia política en el Perú / 1980-1999. Lima: Fondo Editorial del Congreso del Perú.

MILLS, Sara (1997). Discourse. Londres: Routledge.

NUGENT, Guillermo (2001). “¿Cómo pensar en público? / Un debate pragmatista con el tutelaje castrense y clerical”. En López Maguiña, Santiago; Gonzalo Portocarrero; Rocío Silva Santisteban y Víctor Vich (eds.) Estudios culturales: discursos, poderes, pulsiones. Lima: Red para el Desarrollo de las Ciencias Sociales en el Perú, pp. 121-142.

NUGENT, Guillermo (2010). El orden tutelar / Sobre las formas de autoridad en América Latina. Lima: Centro de Estudios y Promoción y Desarrollo, Desco, y Consejo Latinoamericano de Ciencias Sociales.

VAN DIJK, Teun (2000). "El discurso como interacción en la sociedad”. En Van Dijk, Teun (comp.) El discurso como interacción social / Estudios del discurso: introducción multidisciplinaria (vol. ii). Lima: Gedisa, pp. 19-66.

VILLORO, Luis (1998). Estado plural, pluralidad de culturas. México: Paidós Mexicana, S. A.

ZAVALA, Virginia y Gavina Córdova (2010). Decir y callar / Lenguaje, equidad y poder en la universidad peruana. Lima: Fondo Editorial de la Pontificia Universidad Católica del Perú.

ZAVALA, Virginia y Roberto Zariquiey (2007). "“Yo te segrego a ti porque tu falta de educación me ofende": una aproximación al discurso racista en el Perú contemporáneo». En Van Dijk, Teun (comp.) Racismo y discurso en América Latina. Barcelona: Gedisa; pp. 333-369.

ŽIŽEK, Slavoj (2006). Visión de paralaje. Buenos Aires: Fondo de Cultura Económica. 